\title{
Deadly progress: changes in Australian Aboriginal and Torres Strait Islander adult daily smoking, 2004-2015
}

\author{
Raymond Lovetta,e, Katherine A Thurbera ${ }^{a}$, Alyson Wrighta, \\ Raglan Maddox ${ }^{b, c}$ and Emily Banksa,d
}

a National Centre for Epidemiology and Population Health, Research School of Population Health, The Australian National University, Canberra, ACT

b Well Living House, Centre for Urban Health Solutions, Li Ka Shing Knowledge Institute, St Michael's Hospital, Toronto, Ontario, Canada

c Faculty of Health, University of Canberra, ACT, Australia

d Sax Institute, Sydney, NSW, Australia

e Corresponding author: raymond.lovett@anu.edu.au

\section{Article history}

Publication date: December 2017 Citation: Lovett R, Thurber KA, Wright A, Maddox R, Banks E. Deadly progress: changes in Australian Aboriginal and Torres Strait Islander adult daily smoking, 2004-2015. Public Health Res Pract. 2017;27(5):e2751742. https://doi. org/10.17061/phrp2751742

\section{Key points}

- Analysis of national datasets indicates that daily smoking prevalence among Aboriginal and Torres Strait Islander adults decreased by 8.6 percentage points (from $50.0 \%$ in $2004-05$ to $41.4 \%$ in 2014-15), with particular success observed among younger adults and in urban/regional areas

- This reduction corresponds to an estimated 35000 fewer Aboriginal and Torres Strait Islander adult daily smokers in 2014-15 compared with if smoking prevalence had remained stable since 2004-05, leading to thousands of lives saved

- Continued resourcing and comprehensive tobacco control efforts are required to continue and accelerate progress

\section{Abstract}

Background: Tobacco smoking is the leading contributor to the burden of disease among Aboriginal and Torres Strait Islander Australians. Reducing tobacco use in this population is a public health priority. Precise monitoring of smoking prevalence trends is central to implementation and evaluation of effective tobacco control. The way in which trends are reported influences understanding of the extent of progress, with potential implications for policy. Our objective was to quantify absolute changes in Aboriginal and Torres Strait Islander adult ( $\geq 18$ years old) daily tobacco smoking prevalence from 2004 to 2015 , including comparisons with the total Australian population, and by age, sex and remoteness.

Methods: We analysed multiple nationally representative surveys of the Aboriginal and Torres Strait Islander, and total Australian, population conducted from 2004 to 2015. Aligned with strength-based approaches, we applied a progress frame, focusing on absolute differences in smoking prevalence within the Aboriginal and Torres Strait Islander population.

Results: The prevalence of current daily smoking among Aboriginal and Torres Strait Islander adults nationally was 50.0\% (95\% confidence interval [Cl] 47.9, 52.2) in 2004-05 and 41.4\% (95\% Cl 39.1, 43.6) in 2014-15, representing an absolute prevalence decrease of 8.6 percentage points $(95 \% \mathrm{Cl} 5.5,11.8)$ over the past decade. This is comparable with the 6.8 percentage point $(95 \% \mathrm{Cl} 5.6,7.9)$ decrease in smoking prevalence in the total Australian population over the same period, from 21.3\% in 2004-05 $(95 \% \mathrm{Cl} 20.5,22.0)$ to $14.5 \%$ in $2014-15$ (95\% Cl 13.6, 15.4). Particular success in reducing Aboriginal and Torres Strait Islander daily smoking was observed among younger age groups, with a decrease of 13.2 percentage points for 18-24-year-olds (95\% Cl 5.9, 20.4), 9.0 percentage points for 25-34-year-olds $(95 \% \mathrm{Cl} 2.7,15.3)$ and 8.7 percentage points 
for 35-44-year-olds $(95 \% \mathrm{Cl} 2.6,14.8)$. Smoking prevalence in those living in urban/regional areas decreased by 10.2 percentage points $(95 \% \mathrm{Cl} 6.2,14.1)$.

Conclusions: Substantial progress has been made in reducing smoking, with an estimated 35000 fewer Aboriginal and Torres Strait Islander adults smoking every day in 2014-15 compared with if daily smoking remained at 2004-05 prevalence. This will lead to thousands of lives saved. The observed success in the younger age groups is encouraging. Continued resourcing and comprehensive tobacco control efforts are required to ensure positive trends continue.

\section{Introduction}

Tobacco use is the leading contributor to the burden of disease among Aboriginal and Torres Strait Islander people, including through its association with respiratory diseases, cancer and cardiovascular diseases. ${ }^{1}$ Among Australian adults aged 45 years and older, the estimated risk of premature mortality for current smokers is threefold that of never-smokers ${ }^{2}$; however, we lack evidence specific to Aboriginal and Torres Strait Islander people.

Current daily smoking prevalence is estimated at $41.4 \%$ among Aboriginal and Torres Strait Islander adults ( $\geq 18$ years old), compared with $14.5 \%$ among adults in the total Australian population. ${ }^{3}$ Reducing tobacco use will generate substantial health benefits for Aboriginal and Torres Strait Islander people. Recognition of this has led to the development of Aboriginal and Torres Strait Islander tobacco control policies and programs. ${ }^{4-6}$ The Council of Australian Governments set a target to halve the prevalence of Aboriginal and Torres Strait Islander adult daily smoking by 2018 , from the base level of $47.7 \%$ in $2008 .{ }^{6}$

It is critical to have a comprehensive understanding of smoking trends in this population to assess the extent of progress in reducing smoking, provide insight into future trends, and identify areas of success and those requiring additional support. ${ }^{7}$ However, reporting on smoking prevalence and the extent of progress has been inconsistent due to differences in definitions, analytical methods and baseline measures. ${ }^{5,6,8}$ The choice of strategy used to report on trends in health and health inequalities can influence understanding of the extent of progress, with implications for policy. ${ }^{9-12}$ For example, reports have focused on prevalence of Aboriginal and Torres Strait Islander smoking relative to prevalence of smoking in the non-Indigenous Australian population. ${ }^{5}$ This disparity framing is problematic because it discounts progress made within the Aboriginal and Torres Strait Islander population, and may elicit negative emotional and behavioural responses. ${ }^{13,14}$ Therefore, we focus on smoking prevalence reductions in absolute terms, which corresponds to the absolute number of people quitting or not taking up smoking, and to the absolute burden of tobacco-related harm.

Our aim was to quantify absolute changes in daily smoking prevalence among Aboriginal and Torres
Strait Islander adults from 2004 to 2015, including in comparison to the total Australian population, and to examine within-population variation over time by sex, remoteness and age group. Aboriginal and Torres Strait Islander people commonly use the term 'deadly' to mean 'good'; hence, we describe the observed smoking prevalence reduction as 'deadly progress'.

\section{Methods}

\section{Study population}

We analysed nationally representative data from crosssectional health and social surveys conducted between 2004 and 2015. Data were obtained from the 2004-05 National Aboriginal and Torres Strait Islander Health Survey (NATSIHS), 2008 National Aboriginal and Torres Strait Islander Social Survey (NATSISS), 2012-13 Australian Aboriginal and Torres Strait Islander Health Survey, and 2014-15 NATSISS. Where comparisons were made to the total Australian population, data were obtained from the National Health Survey in 2004-05, 2007-08, 2011-12 and 2014-15. Supplementary Table 1 (available from: http://hdl.handle.net/1885/132931) provides details on the data sources.

\section{Data and variables}

Participants were asked if they currently smoked cigarettes. Smokers were asked if they smoked daily, weekly or less frequently. This paper focuses on 'current daily smokers' for consistency with established targets. Participants' age (categorised as 18-24, 25-34, 35-44, 45-54, 55-64 or $\geq 65$ years) and sex were recorded. Remoteness was defined using the 2011 Australian Statistical Geography Standard classification, based on the location at which respondents were enumerated, categorised as urban/ regional (major cities and inner and outer regional) or remote (remote and very remote) areas. Variable and category definitions were consistent across surveys.

\section{Statistical analysis}

We examined changes in Aboriginal and Torres Strait Islander adult daily smoking prevalence from 2004-2015, and examined within-group variation by sex, remoteness 
and age group. We compared daily smoking prevalence and absolute changes in prevalence from 2004-2015 with the total Australian population. We included data from interim time points to provide a comprehensive account of smoking prevalence trends.

All prevalence estimates and 95\% confidence intervals (Cls) were weighted to account for the relevant survey's sampling strategy and nonresponse, using replicate weights provided by the Australian Bureau of Statistics (ABS). ${ }^{15}$ All analyses included the parameter to specify the delete-one jackknife replication method. Prevalence estimates were weighted to the in-scope Australian Aboriginal and Torres Strait Islander and total Australian population to estimate the absolute number of adult current smokers (presented in Supplementary Tables 2 and 3, available from: http://hdl.handle. net/1885/132931). Standard errors (SE) of the prevalence difference were approximated using the formula ${ }^{15}$ : $\mathrm{SE}(x-y)=\left[\operatorname{SE}(x)^{2}+\operatorname{SE}(y)^{2}\right]^{1 / 2}$; associated two-sided $p$-values were calculated from these estimates to test significance at the 0.05 level. ${ }^{16}$ To estimate the reduction in the absolute number of adult daily smokers, we compared the actual number of smokers in 2014-15 with the expected number of smokers in 2014-15 if smoking prevalence had remained stable since 2004-05 (calculated by applying the 2004-05 smoking prevalence to the 2014-15 population distribution).

Unit-record data were accessed through the ABS DataLab; analyses were conducted in Stata 13.

\section{Ethics approval and consent to participate}

The conduct of ABS surveys (household interview components) is approved under the Census and Statistics Act 1905. Ethics approval for the current analyses was granted by the Australian Government Department of Health (Protocol 4/2016) and the Australian National University (Protocol 2017/013) Human Research Ethics Committees.

\section{Availability of data and material}

The data that support the findings of this study are available by application to the ABS, with restrictions on their accessibility and use. More information is available at: www.abs.gov.au/websitedbs/d3310114.nsf/home/curf: + about+the+abs+data+laboratory+(absdl)

\section{Results}

Details of the number of survey participants and the samples' representativeness are provided in Supplementary Table 1 (available from: http://hdl.handle. net/1885/132931).

\section{Daily smoking among Aboriginal and Torres} Strait Islander adults and all Australian adults

The prevalence of daily smoking among Aboriginal and Torres Strait Islander adults was 50.0\% (95\% Cl 47.9, $52.2)$ in $2004-05$ and $41.4 \%(95 \% \mathrm{Cl} 39.1,43.6)$ in 2014-15, representing a decrease in prevalence of 8.6 percentage points $(95 \% \mathrm{Cl} 5.5,11.8 ; p<0.01)$ in absolute terms (Figure 1, Table 1). This corresponds to an estimated 35 000-person decrease in the absolute number of Aboriginal and Torres Strait Islander adult daily smokers. The prevalence of daily smoking among adults in the total Australian population was 21.3\% (95\% Cl 20.5, $22.0)$ in $2004-05$ and $14.5 \%(95 \% \mathrm{Cl} 13.6,15.4)$ in 2014-15, representing a decrease of 6.8 percentage points (95\% Cl 5.6, 7.9; $p<0.01)$.

\section{Daily smoking among Aboriginal and Torres Strait Islander adults by age group}

Significant declines in daily smoking prevalence from 2004 to 2015 were observed among Aboriginal and Torres Strait Islander people aged 18-24 (decrease of 13.2 percentage points, from $50.5 \%$ to $37.3 \%$; 95\% Cl 5.9, 20.4; $p<0.01$ ), 25-34 (decrease of

Table 1. Estimated prevalence of daily smoking among Aboriginal and Torres Strait Islander adults and all Australian adults, 2004-2015

\begin{tabular}{|c|c|c|c|c|}
\hline \multirow[b]{2}{*}{ Survey period } & \multicolumn{2}{|c|}{ Aboriginal and Torres Strait Islander population } & \multicolumn{2}{|c|}{ Total Australian population } \\
\hline & $\begin{array}{l}\text { Prevalence of daily } \\
\text { smoking, \% }(95 \% \mathrm{Cl})\end{array}$ & $\begin{array}{l}\text { Number of daily } \\
\text { smokers/total } \\
\text { population ('000s) }\end{array}$ & $\begin{array}{l}\text { Prevalence of daily } \\
\text { smoking, \% }(95 \% \mathrm{Cl})\end{array}$ & $\begin{array}{l}\text { Number of daily } \\
\text { smokers/total } \\
\text { population ('000s) }\end{array}$ \\
\hline 2004 & $50.0(47.9,52.2)$ & $129 / 258$ & $21.3(20.5,22.0)$ & $3180 / 14963$ \\
\hline 2008 & $47.7(45.7,49.7)$ & $139 / 291$ & $18.9(18.0,19.2)$ & $2980 / 15751$ \\
\hline 2012 & $44.4(42.5,46.2)$ & $162 / 366$ & $16.2(15.5,16.8)$ & $2751 / 17042$ \\
\hline 2014 & $41.4(39.1,43.6)$ & $165 / 400$ & $14.5(13.6,15.4)$ & $2570 / 17732$ \\
\hline $\begin{array}{l}\text { Absolute decrease in daily } \\
\text { smoking prevalence, 2004-2015, } \\
\%(95 \% \mathrm{Cl})\end{array}$ & $8.6(5.5,11.8), p<0.01$ & - & $6.8(5.6,7.9), p<0.01$ & - \\
\hline
\end{tabular}


Figure 1. Estimated prevalence of daily smoking among Aboriginal and Torres Strait Islander adults and all Australian adults, 2004-2015

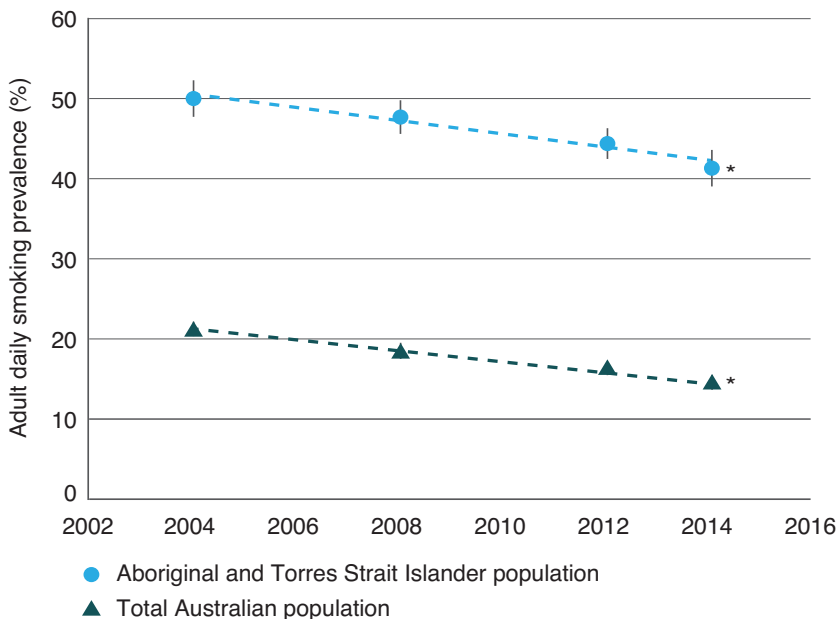

* Indicates a significant within-group decrease between 2004 and 2015

Note: $\quad$ Years along the $x$-axis refer to the survey period, as described in Table 1. Error bars show 95\% confidence intervals.

9.0 percentage points, from $54.6 \%$ to $45.5 \% ; 95 \% \mathrm{Cl} 2.7$, $15.3 ; p<0.01$ ) and $35-44$ years (decrease of

8.7 percentage points, from $55.1 \%$ to $46.4 \%$; $95 \% \mathrm{Cl} 2.6$, 14.8; $p<0.01$ ) (Figure 2). These decreases correspond to an absolute reduction of 12000,9000 and 7000 Aboriginal and Torres Strait Islander daily smokers in the respective age groups. There was no significant change in daily smoking prevalence from 2004 to 2015 among Aboriginal and Torres Strait Islander people aged $45-54$ (decrease of 4.6 percentage points, from $50.5 \%$ to $45.9 \% ; 95 \% \mathrm{Cl}-2.1,11.2 ; p=0.18$ ), 55-64 (increase of 1.3 percentage points, from $34.1 \%$ to $35.4 \% ; 95 \% \mathrm{Cl}-9.7$, $7.1 ; p=0.77$ ) or $\geq 65$ years (increase of 0.9 percentage points, from $23.2 \%$ to $24.1 \% ; 95 \% \mathrm{Cl}-8.9,7.1 ; p=0.84$ ).
Figure 2. Estimated prevalence of daily smoking among Aboriginal and Torres Strait Islander adults by age group, 2004-2015

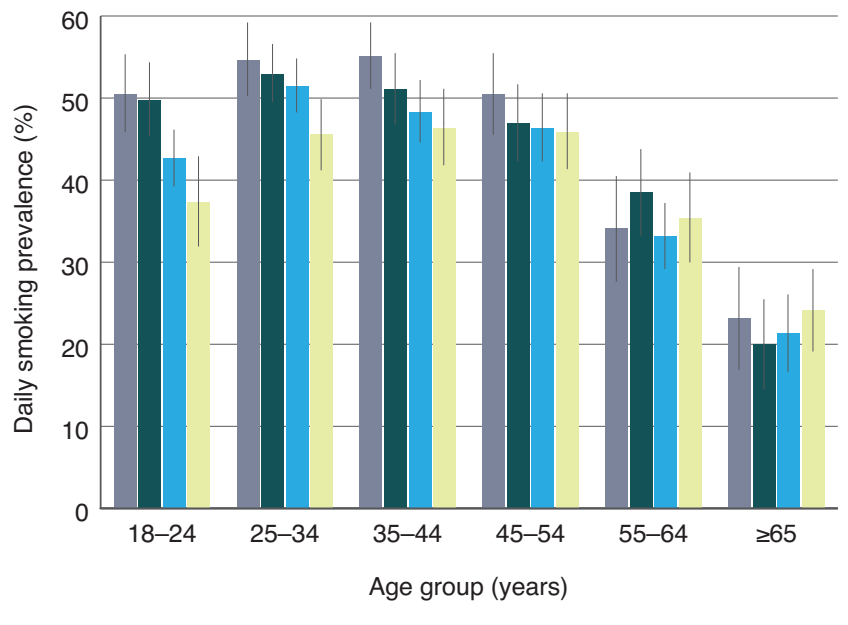

$2004 \square 2008 \square 2012 \square 2014$

Note: Survey periods are described in Table 1. Error bars show $95 \%$ confidence intervals.

\section{Daily smoking among Aboriginal and Torres Strait Islander adults by sex}

The prevalences of daily smoking among Aboriginal and Torres Strait Islander adults in 2004-05 and 2014-15 were $51.3 \%(95 \% \mathrm{Cl} 48.0,54.6)$ and $43.9 \%(95 \% \mathrm{Cl} 40.4,47.4)$ for males (decrease of 7.4 percentage points; $95 \% \mathrm{Cl} 2.7$, 12.2; $p<0.01)$ and $48.9 \%(95 \% \mathrm{Cl} 46.1,51.8)$ and $39.1 \%(95 \% \mathrm{Cl} 36.4,41.9)$ for females (decrease of 9.8 percentage points; $95 \% \mathrm{Cl} 5.8,13.8 ; p<0.01$ ) (Figure 3). These significant decreases correspond to 14000 fewer male and 21000 fewer female Aboriginal and Torres Strait Islander adult daily smokers.

Figure 3. Estimated adult daily smoking prevalence in Aboriginal and Torres Strait Islander adults by sex (left) and remoteness (right), 2004-2015
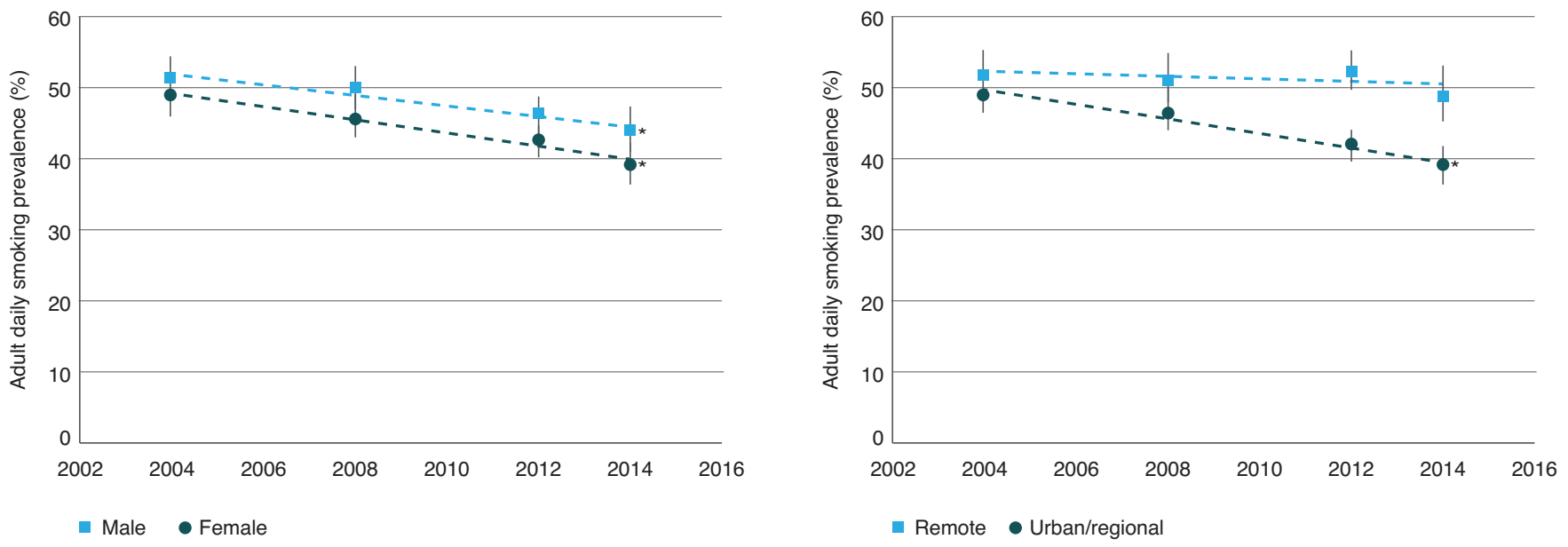

* Indicates a significant within-group decrease between 2004 and 2015.

Note: Years along the $x$-axis refer to the survey period, as described in Table 1. Error bars show 95\% confidence interval. 


\section{Daily smoking among Aboriginal and Torres}

\section{Strait Islander adults by remoteness}

The prevalence of daily smoking in urban/regional settings was $49.3 \%(95 \% \mathrm{Cl} 46.5,52.1)$ in $2004-05$ and $39.1 \%(95 \% \mathrm{Cl} 36.4,41.9)$ in $2014-15$ (Figure 3$)$. This absolute decrease of 10.2 percentage points $(95 \% \mathrm{Cl} 6.2$, $14.1 ; p<0.01$ ) in daily smoking prevalence corresponds to an estimated reduction of 32000 Aboriginal and Torres Strait Islander daily adult smokers in urban/regional settings. In remote areas, the prevalence of daily smoking among adults was $51.9 \%(95 \% \mathrm{Cl} 48.6,55.3)$ in 2004-05 and $49.3 \%(95 \% \mathrm{Cl} 45.3,53.2)$ in $2014-15$, with no significant change (decrease of 2.6 percentage points; $95 \% \mathrm{Cl}-2.5,7.8 ; p=0.32)$.

\section{Daily smoking among Aboriginal and Torres}

\section{Strait Islander adults by sex and remoteness}

Similar patterns emerged when examining trends in daily smoking among urban/regional versus remote adults by sex (Figure 4). The prevalence of daily smoking among male and female adults in urban/regional settings decreased significantly from 2004 to 2015 by 7.5 percentage points $(95 \% \mathrm{Cl} 1.6,13.5 ; p=0.01)$ and 12.6 percentage points $(95 \% \mathrm{Cl} 7.6,17.5 ; p<0.01)$, respectively. This corresponds to a decrease of approximately 11000 male and 20000 female daily adult smokers in urban/regional areas. There was no significant change in daily smoking prevalence among males (decrease of 4.5 percentage points; $95 \% \mathrm{Cl}-2.7,11.6$; $p=0.22$ ) or females (decrease of 1.1 percentage points; $95 \% \mathrm{Cl}-5.6,7.9 ; p=0.75$ ) in remote areas.

\section{Discussion}

The prevalence of daily smoking among Aboriginal and Torres Strait Islander adults in Australia has decreased by 8.6 percentage points $(95 \% \mathrm{Cl} 5.5,11.8)$, from $50.0 \%$ in 2004-05 to $41.4 \%$ in 2014-15. This corresponds to an estimated 35000 fewer Aboriginal and Torres Strait Islander adult daily smokers in 2014-15, compared with if the smoking prevalence had remained stable since 200405. Our findings indicate that thousands of premature deaths in Aboriginal and Torres Strait Islander people have been prevented by the reduction in daily smoking prevalence over the past decade. Accurately determining the number of deaths averted requires additional data, such as cause-specific mortality. Declines in daily smoking among Aboriginal and Torres Strait Islander people were observed among both males and females, and were most evident among those aged 18-44 years, and those living in urban/regional areas.

The absolute decrease in smoking prevalence observed in the Aboriginal and Torres Strait Islander population is comparable with the decrease of 6.8 percentage points $(95 \% \mathrm{Cl} 5.6,7.9)$ in the total Australian population over the same period, although the base smoking prevalence was substantially lower in the total Australian population (21.3\% in 2004-05). These results demonstrate that considerable progress has been made in the Aboriginal and Torres Strait Islander population in the past decade, matching in absolute terms the extent of progress made in the total Australian population.

Given the similar absolute decrease in smoking prevalence in the Aboriginal and Torres Strait Islander and total Australian population, the gap in smoking prevalence has remained relatively stable. This may appear inconsistent with the Australian Institute for Health and Welfare's midterm report for the National Tobacco

Figure 4. Estimated adult daily smoking prevalence in Aboriginal and Torres Strait Islander people by remoteness among males (left) and females (right), 2004-2015
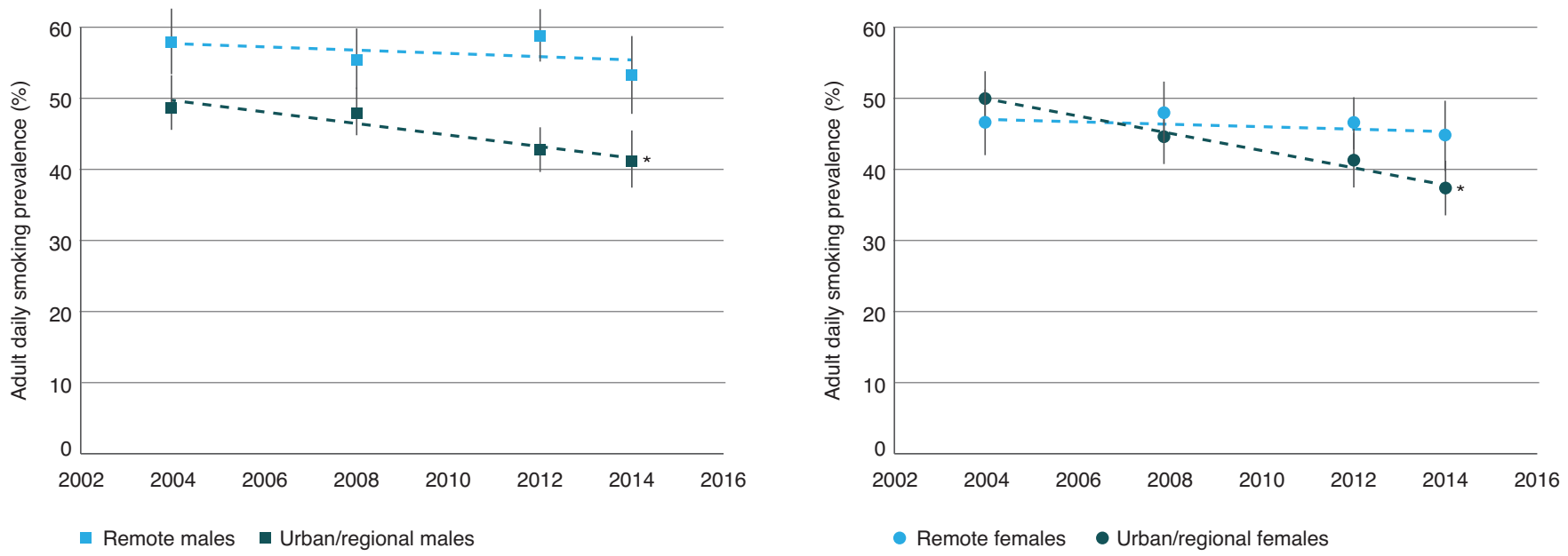

* Indicates a significant within-group decrease between 2004 and 2015.

Note: Years along the $\mathrm{x}$-axis refer to the survey period, as described in Table 1. Error bars show $95 \%$ confidence intervals. 
Strategy 2012-20185, which reported that the gap in smoking between Aboriginal and Torres Strait Islander people and non-Indigenous Australians had increased between 2008 and 2015. The discrepancy arises from different methods used to report trends in smoking inequalities. ${ }^{9-11}$ Our analysis emphasises change in the absolute prevalence of smoking within the population $(50.0 \%-41.4 \%=8.6 \%$ absolute prevalence decrease $)$, whereas the midpoint report emphasises smoking prevalence in the Aboriginal and Torres Strait Islander population relative to the non-Indigenous population. ${ }^{5}$ In relative terms, the ratio of Aboriginal and Torres Strait Islander to total Australian smoking prevalence increased from 2.4 (50.0\%:21.3\%) in 2004-05 to 2.9 (41.4\%:14.5\%) in 2014-15. This demonstrates that reporting change in absolute versus relative terms can lead to fundamentally different conclusions, which could affect support for programs and policies. ${ }^{9-12}$ Focusing on relative differences in isolation can obscure progress at the population level; that is, the absolute number of Aboriginal and Torres Strait Islander adults quitting or not taking up smoking. Further, research from other populations demonstrates that communicating information about health inequity using a progress frame (as used in this paper) rather than a disparity frame (i.e. focusing on the persisting gap) is associated with more positive emotional responses and increased interest in engaging in healthpromoting behaviours. ${ }^{14}$ Therefore, we consider it ethical to report absolute progress in smoking prevalence.

The ambitious target to halve Aboriginal and Torres Strait Islander adult daily smoking prevalence to $23.9 \%$ by $2018^{6}$ will not be achieved if current trends continue. However, this target would be reached within the next two decades if smoking prevalence continues to decrease at the current rate. If the success in smoking reduction observed within the younger age groups and those living in urban/regional areas is echoed in older age groups and in remote areas, this target may be reached earlier.

We observed significant reductions (about 10\%) in daily smoking prevalence among the youngest age groups (18-24, 25-34 and 35-44 years). Data from the 2004-05 NATSIHS indicates that two-thirds of current and past Aboriginal and Torres Strait Islander smokers had begun smoking by age $18^{17}$; therefore, our findings of reduced smoking prevalence among younger adults is promising. The Aboriginal and Torres Strait Islander population has a younger age profile than the total population, and therefore the potential population-level benefit of reducing smoking among younger adults is important. ${ }^{18}$

We observed reductions in daily smoking prevalence among male and female Aboriginal and Torres Strait Islander adults living in urban/regional areas. Given that the majority of Aboriginal and Torres Strait Islander people live in urban/regional settings, this is another encouraging finding at the population level. We did not detect a significant change between 2004-05 and 2014-15 in daily smoking prevalence among Aboriginal and Torres Strait Islander adults living in remote areas. The observed stability of smoking prevalence in remote areas from 2004 to 2015 is consistent with trends from 1994 to $2004 .^{7}$ Despite being the largest available datasets, the number of survey participants in remote areas was relatively small, and is likely to be insufficient to detect changes in prevalence.

Given the enduring high smoking prevalence among older age groups and in remote settings, improved intensive effort will be required to change the normalisation of tobacco use and correct potential misperceptions of tobacco use, particularly as older people may have had longer and more intense exposure to tobacco marketing. ${ }^{19}$ This includes continued and concerted effort from targeted Aboriginal and Torres Strait Islander tobacco control programs, in addition to national strategies. ${ }^{4,20}$

The prevalence of smoking is reduced by increased numbers of people quitting and not taking up smoking. Since 2008, there has been a concerted effort in public health strategies, policies and programs to reduce tobacco smoking in Aboriginal and Torres Strait Islander people. Australia's approach to tobacco control is comprehensive, and it is difficult to attribute changes to one program; however, continuing support for both wholeof-population and targeted strategies is required. For example, recent evidence indicates that the introduction of graphic warning labels on cigarette packages led to increased understanding of and concern about the harms associated with smoking among Aboriginal and Torres Strait Islander people ${ }^{19,21}$, and research has demonstrated that smokers' knowledge of the effects of secondhand smoke is associated with desire and attempts to quit. ${ }^{22}$ Our findings may indicate that programs and policies have been particularly effective at reducing smoking among young people and those living in urban/ regional areas. It is more difficult to assess the potential effectiveness of programs and policies in remote settings; finer regional estimates are required to assess policy and program impacts in this setting. ${ }^{23}$

\section{Strengths and weaknesses}

This paper analyses multiple cross-sectional data, which are the most comprehensive data available on Aboriginal and Torres Strait Islander smoking status. Limitations of our approach include that comparability between survey estimates may be affected by differences in scope, sample design, coverage, and potential changes in the age structure of the population over time. The use of weighting generates estimates that are representative of the in-scope population, which were similarly defined across the four surveys. However, we note that the 2004-05 and 2008 surveys represent a somewhat smaller percentage (82$90 \%$ ) of the Aboriginal and Torres Strait Islander population compared with the other surveys (95\%); this may result from issues related to survey scope. ${ }^{17}$ 
We have restricted our analysis to current daily smoking - rather than including weekly or less frequent smoking - to enable consistent measurement across surveys, and to enable direct comparison with national tobacco targets. ${ }^{5,6}$ It is important to note that our analysis focused on cigarette smoking. Recent ABS surveys provide data on the use of other tobacco products (e.g. chewing tobacco); data on e-cigarette use are not yet available.

Although we include a comparison with daily smoking prevalence in the total Australian population as a benchmark, this article focuses on variation in daily current smoking trends within the Aboriginal and Torres Strait Islander population. We have presented comparable estimates for the total Australian population, rather than the non-Indigenous Australian population, because of the data that were available, and we may therefore underestimate the gap in prevalence between the Aboriginal and Torres Strait Islander and nonIndigenous populations. However, this underestimation is likely to be very small; for example, in 2014, the difference between daily adult smoking prevalence in the nonIndigenous population (14.2\%; $95 \% \mathrm{Cl} 13.4,15.0)^{3}$ versus the total Australian population $(14.5 \% ; 95 \% \mathrm{Cl} 13.6,15.4)$ was marginal.

\section{Conclusions}

Applying a progress frame rather than a disparity frame and reporting absolute changes in smoking prevalence provides clear evidence of the substantial and significant declines in daily smoking prevalence among Aboriginal and Torres Strait Islander adults, which will result in considerable health gain. Particular success has occurred among younger adults and those living in urban/ regional areas.

Despite this progress, the smoking prevalence in the Aboriginal and Torres Strait Islander population remains high, with an estimated 165000 current adult daily smokers. It will be critical to learn from the success among younger adults and those in urban areas to effect change among older age groups and those in remote areas. Continuation and enhancement of a suite of tobacco control efforts are required.

\section{Acknowledgements}

The authors acknowledge and thank all participants in the ABS national surveys, and acknowledge the statistical advice provided by Dr Alice Richardson at the National Centre for Epidemiology and Population Health.

This work was supported by the National Health and Medical Research Council of Australia (EB, grant number 1042717; RL, 1088366). AW is supported through a scholarship from the Australian Government Department of Health. The funding bodies had no role in the design of the study, analysis, interpretation of data, or writing the manuscript.

\section{Competing interests}

None declared

\section{Author contributions}

$R L, E B$, and $R M$ conceived the manuscript. KT and AW analysed the data. $R L$ and $K T$ interpreted the data. $R L$ and KT drafted the manuscript. All authors provided critical input into the manuscript and approved the final version.

\section{References}

1. Australian Institute of Health and Welfare. Australian Burden of Disease Study: impact and causes of illness and death in Aboriginal and Torres Strait Islander people 2011. Canberra: AlHW; 2016 [cited 2017 Oct 26]. Available from: www.aihw.gov.au/getmedia/e31976fcadcc-4612-bd08-e54fd2f3303c/19667-bod7-atsi-2011. pdf.aspx?inline $=$ true

2. Banks E, Joshy G, Weber MF, Liu B, Grenfell R, Egger S, et al. Tobacco smoking and all-cause mortality in a large Australian cohort study: findings from a mature epidemic with current low smoking prevalence. BMC Med. 2015;13:38.

3. Australian Bureau of Statistics. National Aboriginal and Torres Strait Islander Social Survey, 2014-15. Canberra: ABS; 2016 [cited 2017 Jan 9]. Available from: www.abs. gov.au/ausstats/abs@.nsf/mf/4714.0

4. Scollo M, Winstanley M. Tobacco in Australia: facts and issues. Melbourne: Cancer Council Victoria; 2012 [cited 2017 Oct 26]. Available from: www.tobaccoinaustralia. org.au

5. Australian Institute of Health and Welfare. Tobacco indicators: measuring midpoint progress—reporting under the National Tobacco Strategy 2012-2018. Canberra: AlHW; 2016 [cited 2017 Oct 26]. Available from: www.aihw.gov.au/getmedia/fcf4f834-8ef8-44a099cb-8fc28150428d/20065.pdf.aspx?inline=true

6. Intergovernmental Committee on Drugs. National tobacco strategy 2012-2018. Canberra: Commonwealth of Australia; 2012 [cited 2017 Oct 26]. Available from: www.nationaldrugstrategy.gov.au/internet/drugstrategy/ publishing.nsf/Content/D4E3727950BDBAE4CA257AE7 0003730C/\$File/National\%20Tobacco\%20Strategy\%20 2012-2018.pdf

7. Thomas DP. Smoking prevalence trends in Indigenous Australians, 1994-2004: a typical rather than an exceptional epidemic. Int J Equity Health. 2009;8:37.

8. Department of the Prime Minister and Cabinet. Closing the gap prime minister's report 2017. Canberra, ACT: Commonwealth of Australia; 2017 [cited 2017 Oct 26]. Available from: closingthegap.pmc.gov.au/sites/default/ files/ctg-report-2017.pdf 
9. King NB, Harper S, Young ME. Use of relative and absolute effect measures in reporting health inequalities: structured review. BMJ. 2012;345:e5774.

10. Niederdeppe J, Bigman CA, Gonzales AL, Gollust SE. Communication about health disparities in the mass media. J Communication. 2013;63:8-30.

11. Harper S, Lynch J: Health inequalities: measurement and decomposition. SSRN; 2016 [cited 2017 Oct 27] Available from: papers.ssrn.com/sol3/papers. cfm?abstract_id=2887311

12. Blakely T, Disney G, Atkinson J, McDonald A, Mackenbach JP. A typology for charting socio-economic mortality gradients: "go south-west". Epidemiol. 2017;28:594-603.

13. Williams DR, Purdie-Vaughns V. Needed interventions to reduce racial/ethnic disparities in health. J Health Polit Policy Law. 2016;41(4):627-51.

14. Nicholson RA, Kreuter MW, Lapka C, Wellborn R, Clark EM, Sanders-Thompson V, et al. Unintended effects of emphasizing disparities in cancer communication to African-Americans. Cancer Epidemiol Biomarkers Prev. 2008;17(11):2946-53.

15. Australian Bureau of Statistics. Canberra: ABS; 2017 Standard errors and replicate weights; 2015 Mar 5 [cited 2017 Sep 20]. Available from: www.abs.gov.au/ausstats/ abs@.nsf/Lookup/4363.0.55.001Technical+Note12011-13

16. Altman DG, Bland JM. How to obtain the $P$ value from a confidence interval. BMJ. 2011;343:d2304.
17. Australian Bureau of Statistics. National Aboriginal and Torres Strait Islander Health Survey 2004-05. Canberra: ABS; 2006 [cited 2017 Feb 7]. Available from: www.abs. gov.au/ausstats/abs@.nsf/mf/4715.0/

18. Australian Bureau of Statistics: Census of Population and Housing: counts of Aboriginal and Torres Strait Islander Australians, 2011. Canberra: ABS; 2012 [cited 2017 Feb 8]. Available from: www.abs.gov.au/ausstats/ abs@.nsf/mf/2075.0

19. Maddox R, Durkin S, Lovett R. Plain packaging implementation: perceptions of risk and prestige of cigarette brands among Aboriginal and Torres Strait Islander people. Aust N Z J Public Health. 2015;40(3):221-5.

20. Johnston V, Thomas DP. What works in Indigenous tobacco control? The perceptions of remote Indigenous community members and health staff. Health Promot $J$ Aust. 2010;21:45-50.

21. Nicholson A, Borland R, Bennet P, Davey M, Sarin J, Van der Sterren A, et al. The effect of pack warning labels on quitting and related thoughts and behaviours in a national cohort of Aboriginal and Torres Strait Islander smokers. NicotineTob Res. 2017;19(10):1163-71.

22. Nicholson AK, Borland R, Couzos S, Stevens M, Thomas DP. Smoking-related knowledge and health risk beliefs in a national sample of Aboriginal and Torres Strait Islander people. Med J Aust. 2015;202(1):S45-50.

23. Wright A, Lovett R, Roe Y, Richardson A. Enhancing national data to align with policy objectives: Aboriginal and Torres Strait Islander smoking prevalence at finer geographic levels. Aust Health Review. 2017. Epub 2017 Jun 5 .

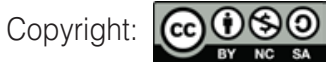

(c) 2017 Lovett et al. This article is licensed under the Creative Commons Attribution-NonCommercial-ShareAlike 4.0 International Licence, which allows others to redistribute, adapt and share this work non-commercially provided they attribute the work and any adapted version of it is distributed under the same Creative Commons licence terms. See: www.creativecommons.org/licenses/by-nc-sa/4.0/ 